\title{
Erratum: Functional Prions in the Brain
}

\section{Joseph B. Rayman and Eric R. Kandel}

When this article was first published, the three multiplication symbols in Figure 4 appeared as boxes due to a typesetter error. The publisher apologizes for this error. A corrected version of Figure 4 is below. In addition, the multiplication symbols have been restored to Figure 4 in the current PDF and full-text versions of the article.
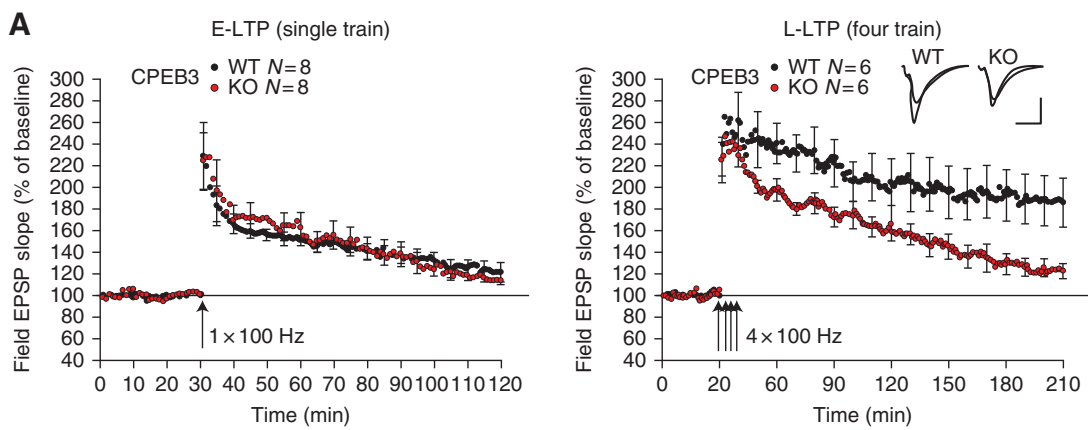

B
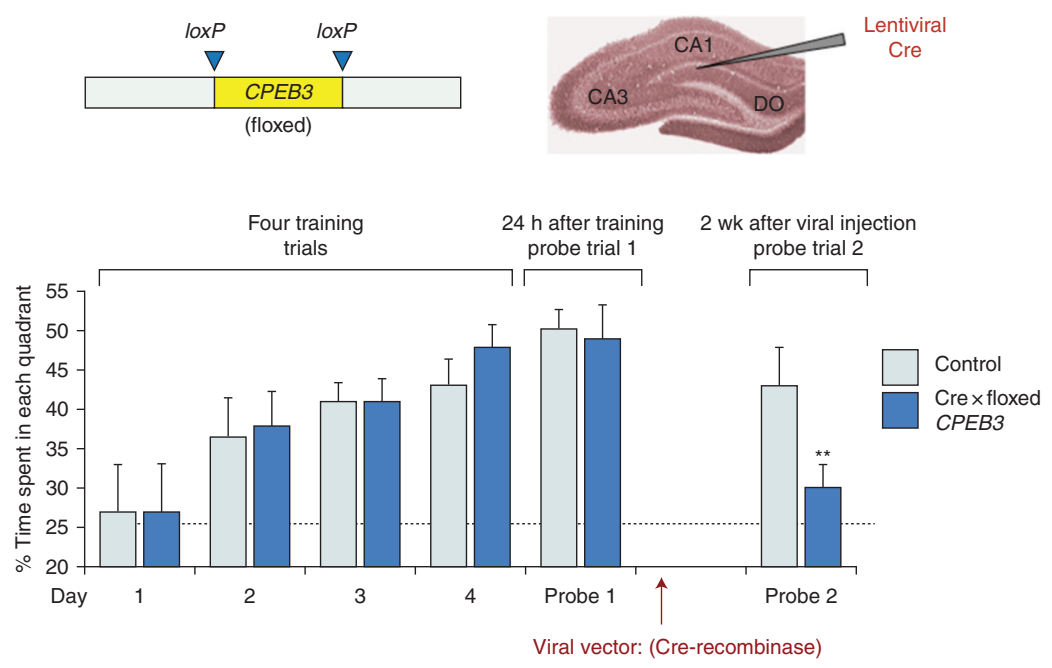

Figure 4. Mouse CPEB-3 is required for both normal long-term potentiation in the hippocampus and maintenance of long-term spatial memory. (A) Mouse CPEB-3 is required for the maintenance of protein synthesisdependent long-term potentiation (LTP) induced by strong tetanic stimulation $(4 \times 100 \mathrm{~Hz})$, but is dispensable for early-phase LTP induced by a single $100 \mathrm{~Hz}$ train. (B) Conditional deletion of CPEB-3 by injection of a Cre recombinase lentivirus into the mouse hippocampus prevents reconsolidation following memory retrieval. 


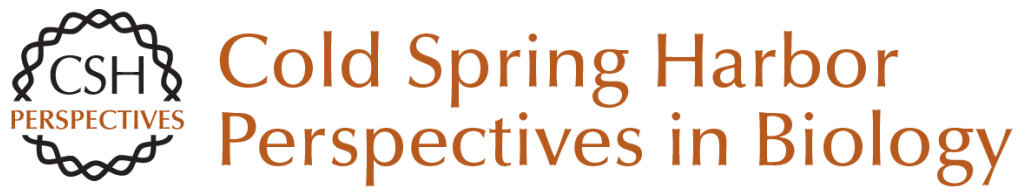

\section{Erratum: Functional Prions in the Brain}

Joseph B. Rayman and Eric R. Kandel

Cold Spring Harb Perspect Biol 2017; doi: 10.1101/cshperspect.a033597

Subject Collection Prion Biology

\section{Genetic PrP Prion Diseases}

Mee-Ohk Kim, Leonel T. Takada, Katherine Wong, et al.

\section{Neurodegenerative Disease Transmission and Transgenesis in Mice Brittany N. Dugger, Daniel P. Perl and George A. Carlson}

Toward the Atomic Structure of PrPSc Jose A. Rodriguez, Lin Jiang and David S. Eisenberg

Bioassays and Inactivation of Prions Kurt Giles, Amanda L. Woerman, David B. Berry, et al.

Functional Prions in the Brain Joseph B. Rayman and Eric R. Kandel

The Amyloid Phenomenon and Its Links with Human Disease Christopher M. Dobson

Tau Positron Emission Tomography Imaging Hartmuth C. Kolb and José Ignacio Andrés
Clinical Neurology and Epidemiology of $t$ Neurodegenerative Diseases Michael G. Erkkinen, Mee-Ohk Kim and N Geschwind

Prion Properties of SOD1 in Amyotrophic Sclerosis and Potential Therapy Caroline Sibilla and Anne Bertolotti

\section{Mapping Neurodegenerative Disease Ons Progression William W. Seeley}

Erratum: Functional Prions in the Brain Joseph B. Rayman and Eric R. Kandel

Pathology of Neurodegenerative Disease: Brittany N. Dugger and Dennis W. Dicksol

TIA-1 Is a Functional Prion-Like Protein Joseph B. Rayman and Eric R. Kandel Molecular Genetics of Neurodegenerative
Dementias Flora I. Hinz and Daniel H. Geschwind

For additional articles in this collection, see http://cshperspectives.cshlp.org/cgi/collection/

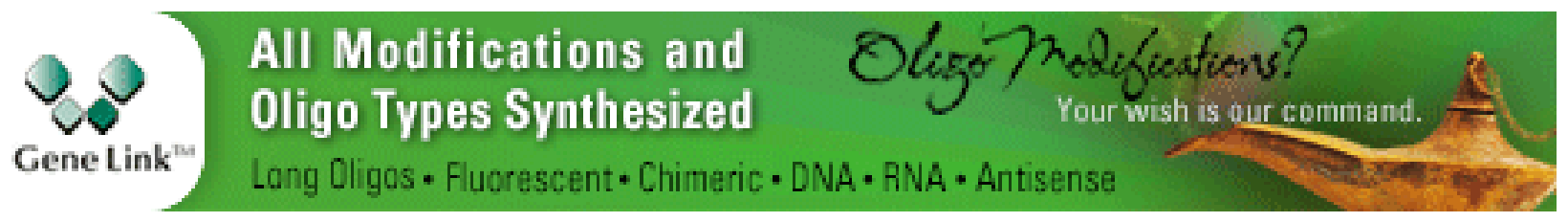

Copyright @ 2017 Cold Spring Harbor Laboratory Press; all rights reserved 
Prion-Like Polymerization in Immunity and Inflammation

Xin Cai, Hui Xu and Zhijian J. Chen
Cross- $\beta$ Polymerization of Low Complexit Sequence Domains

Masato Kato and Steven L. McKnight

For additional articles in this collection, see http://cshperspectives.cshlp.org/cgi/collection/

\section{All Modifications and Oligo Types Synthesized \\ Oligo medifications? \\ Your Wish is our command.}

